\title{
DOSSIÊ RECRUTAMENTO POLÍTICO E SELEÇÃO DE CANDIDATOS NAS DEMOCRACIAS CONTEMPORÂNEAS
}

\author{
Maria do Socorro Sousa Braga
}

Bruno Bolognesi

\begin{abstract}
"Num momento em que os políticos estão sendo cada vez mais objeto de crítica, é importante lançar luz sobre um dos mais dificeis obstáculos que os aspirantes devem superar."
\end{abstract}

(RUSH, 1969).

$\mathrm{Na}$ vasta bibliografia especializada sobre os fenômenos político-partidários a relação entre recrutamento político e seleção de candidatos foi, quase sempre, tratada como duas esferas que estavam temporalmente e objetivamente interligadas. Nesses estudos a seleção de candidatos era, na verdade, uma das dimensões do processo de formação das elites políticas. Com o advento do neo-institucionalismo, a separação entre seleção de candidatos e recrutamento político se tornou mais evidente. Isso se deu em função da percepção de que instituições determinam o comportamento dos atores e não só que as instituições são formadas por eles. Essa separação puramente analítica permitiu que os estudos dos processos de seleção de candidatos se descolassem dos de recrutamento, criando assim uma nova frente de pesquisas.

Por outro lado, isso não quer dizer que as pesquisas acerca do recrutamento político foram abandonadas ou deveriam ser. Apenas que novas dimensões e interfaces de convívio surgem a partir da inescapável especialização das atividades acadêmicas.

$\mathrm{O}$ termo recrutamento político pertence à tradição comportamentalista (RAHAT \& HAZAN, 2001). Juntamente com a socialização política, é um dos conceitos centrais para análise dos outputs do sistema político. Segundo Czudnowski (1975), recrutamento político é o processo pelo qual os indivíduos abandonam a sua vida comum e ingressam na vida política. Nesse sentido, a maior parte dos estudos de recrutamento político se voltou para realizar levantamento das diferenças entre as elites e as populações em geral. Estabelecida a diferença, as explicações para tal vão desde estudos históricos mais amplos que esquadrinham as mudanças geracionais nas elites (CAMP, 2001), até estudos mais pontuais como esses apresentados neste dossiê.

Nesta linha de pesquisa, a seleção de candidatos seria apenas um aspecto de um fenômeno político maior e mais complexo. Mesmo Czudnowski, que vislumbra as instituições políticas como um aspecto relevante nos estudos de recrutamento, deixa que seu modelo de análise seja teoricamente dominado pelas processos maiores de socialização, entendendo, assim, a seleção dos candidatos como mero resultado desse arranjo. Nas palavras do autor: "[...] considerando os sistemas de seleção como variáveis independentes, somos levados a análises descritivas de pouca relevância teórica" "(CZUDNOWSKI, 1975, p. 228). Isso mostra como os estudos dos anos 1970 tinham sua tradição comportamentalista bem acentuada, preocupando-se mais com os aspectos da socialização do que com o funcionamento das instituições. Apenas ao final dos anos 1980, com a retomada dos estudos institucionais em contexto de democracias seculares ou em países em processos de democratização cada vez mais institucionalizados, houve a preocupação em analisar as diversas dimensões que conformam o recrutamento político, havendo vários estudiosos privilegiando a seleção de candidatos a cargos eletivos.

Entre esses estudos, um dos mais importantes foi o trabalho de Gallagher e Marsh (1988). Para esses autores, os determinantes da seleção de candidatos estavam dados pela interação entre sistema político e a natureza dos partidos. Já Norris (1997) foi capaz de unir a concepção de recrutamento político com a seleção de candidatos oferecendo modelos mais flexíveis de análise. Para isso ela se apropriou de variáveis sociológicas intermediadas pela estrutura de oportunidades das instituições políticas investigadas.

Contudo, é justamente o trabalho de Gallagher e Marsh que dá fôlego e incentivo a maior produção e reinserção do tema nas agendas de pesquisas

1 “...considering selection systems as independent variables leads to descriptive analyses of little theoretical relevance". Tradução dos autores. 
internacionais ao longo dos anos 1990 e adiante. Retomando o modelo, Rahat e Hazan publicam em 2001 um framework de análise adaptável aos países e partidos de democracias representativas. Em uma edição especial do periódico Party Politics, publicada em maio de 2001, vários especialistas dedicaram-se a testar e relacionar esse framework dos autores israelenses em diversos países e diferentes contextos históricos. Os resultados obtidos demonstram a validade e a confiabilidade desses métodos no exame das dimensões que envolvem o processo de seleção de candidatos bem como na identificação de suas consequências no comportamento político das lideranças partidárias e dos possíveis representantes escolhidos.

Reverberando a publicação desse volume da revista Party Politics, uma série de artigos espalhados ao longo do tempo e em diferentes periódicos deram corpo internacionalmente ao tema. A seleção de candidatos passou de mero acessório do recrutamento político a variável independente, sendo utilizada para explicar a importância e vitalidade dos partidos nas democracias representativas (EPSTEIN, 1967; GALLAGHER \& MARSH, 1988), mensurar democracia interna dos partidos (FREIDENBERG, 2003), estabelecer critérios de conteúdo democrático (NORRIS, 1997; RAHAT; HAZAN \& KATZ, 2008) ou ainda, determinar o comportamento dos eleitos (KOOP \& BITTNER, 2011).

No que se refere à América Latina, a derrocada dos regimes ditatoriais a partir dos anos 1980 e a retomada da reconstrução do pluripartidarismo motivaram a realização de vários estudos dirigidos, inicialmente, à análise dos processos de transição de regime e, em um segundo momento, ao desenho da engenharia institucional mais viável para o funcionamento da democracia e para a estabilidade do regime. Após a constatação histórica de que os regimes latinoamericanos mostravam certa regularidade em seu funcionamento, o olhar dos estudiosos se lançou para os procedimentos que conduzem os representantes a seus postos eletivos. Tendo esse objeto de estudo como preocupação analítica, Siavelis e Morgenstern (2008) organizaram o livro Pathways to Power: political recruitment and candidate selection in Latin America, onde os autores apresentam outra metodologia para investigar os determinantes e conseqüências dos processos de seleção de candidatos a cargos eletivos realizados nessa região. Para isso Siavelis e Morgenstern (2008) partem de conceitos centrais elaborados pelos autores europeus e norte-americanos e, mesmo, dos métodos já existentes para reelaborarem e proporem um modelo de análise mais apto aos países da América do Sul.
Finalmente, os estudos realizados no Brasil sobre recrutamento partidário se iniciaram no final dos anos 1960. Nesse período predominaram análises orientadas pela Sociologia Política. Entre os trabalhos desenvolvidos estão os pioneiros estudos de Pitta \& Arruda, (1966); Moreira, (1967); Maduro, (1971; 1973); Leopoldi, (1973; 1977); Nunes, (1977; 1978) que se preocuparam em analisar o perfil social dos candidatos selecionados pelos partidos no estado do Rio de Janeiro. Em nível nacional, cabe destacar a análise de Fleischer (1976) que realizou extenso levantamento sobre as carreiras políticas dos deputados federais e estaduais. Já Schmitter (1971) e Cardoso (1975) pesquisaram os vínculos entre deputados e grupos de interesse. Com a redemocratização e o processo de estabilização das instituições democráticas ao longo dos anos 1990, aumentou o interesse dos estudiosos pelo recrutamento partidário e, especialmente, por uma de suas dimensões, o processo de seleção de candidatos. Mantendo a tradição dos estudos baseados no registro da Sociologia Política estão análises como a de Rodrigues $(2002 ; 2006)$. Mas também por aqui houve a influência da perspectiva teórica do neoinstitucionalismo estimulando novas agendas de pesquisa. Nesse sentido, estão os trabalhos de Santos (1997) e Messemberg (2002). Mais recentemente surgiram análises inspiradas tanto pelos métodos elaborados por Rahat e Hazan (2001), caso do esforço pioneiro de Braga (2009), quanto aqueles mais influenciados por Siavelis e Morgenstern (2008), levado a cabo por Braga e Bolognesi (2013) e Samuels (2008). Ainda nesse contexto está o artigo de Álvares (2008), que agrega algumas dimensões analíticas de Norris (1997).

É a partir desse quadro mais geral do estado da arte dos títulos sobre recrutamento político e, mais particularmente, sobre uma de suas dimensões, o processo de seleção dos candidatos a cargos eletivos, que apresentamos este dossiê, agregando tanto estudo que tem grande contribuição metodológica para nossas pesquisas nacionais quanto análises sobre a formação e extensão da carreira política no Brasil. Outros trabalhos buscam, a partir dos métodos internacionalmente reconhecidos, avaliar o impacto desse processo no funcionamento do sistema partidário da atualidade e na democracia intrapartidária - . configurando, assim, profícua colaboração para o debate sobre a questão da representação no Brasil.

Nesse sentido, o texto de Pippa Norris originalmente publicado em forma de capítulo de livro e aqui traduzido por Bruno Bolognesi - que abre este dossiê, talvez seja o mais próximo de uma possível junção entre recrutamento e formação das listas 
eleitorais. Através da mobilização do modelo da economia neoclássica de oferta e demanda, a autora busca mostrar como a interação entre background social e instituições é possível e necessária para entender a formação dos parlamentos no mundo. Segundo Norris, somente com a interação entre as duas arenas é possível compreender questões fundamentais para as democracias contemporâneas, como a representação política das mulheres.

O trabalho de Clara Araújo e Doriam Borges apresenta valiosa e consistente análise sobre as candidaturas femininas no Brasil. A partir de um escopo completo das variáveis que determinam a representação das mulheres no legislativo nacional, os autores traçam o perfil das vitoriosas em relação aos seus pares homens. A inovação do artigo consiste em apresentar uma gama de variáveis pouco exploradas pela literatura, como motivação política e posse de recursos simbólicos. Além disso, apontam onde estão os principais gargalos que fazem da mulher ainda minoria nas casas legislativas.

Os dois próximos artigos focam no processo de seleção de candidatos à Câmara dos Deputados. O texto de Bruno Bolognesi centra-se na seleção de candidatos dos partidos brasileiros como um processo em si. Buscando o aporte organizacional das arenas intra-partidárias, o texto debate com a literatura que diagnostica os partidos brasileiros como fracos e perniciosos, embora não levem em conta a estrutura organizacional enquanto variável explicativa. Ao privilegiar a vida interna dos partidos políticos, a seleção de candidatos, como mostra o autor, pode ser um indicador qualificado para mensurarmos níveis de democracia interna nos mesmos. Por outro lado, as conclusões apontam que nem sempre procedimentos democráticos levam a conteúdos democráticos.

O artigo de Maria do Socorro Sousa Braga e Oswaldo Amaral demonstra como os partidos brasileiros vêm mantendo sua vitalidade ao controlar as portas de acesso às arenas políticas no Brasil. Verifica-se que, por meio do processo de seleção, as organizações partidárias continuam realizando a articulação entre os cidadãos e as esferas de poder politico. Para isso identificam tanto os fatores que afetam essa dimensão do recrutamento partidário a cargos eletivos proporcionais, como também suas consequências para o sistema partidário. Mostram, portanto, que há uma coordenação envolvendo o número de candidatos, o espaço geográfico em que competem e o seu perfil socioocupacional, além da própria distribuição de recursos partidários.

Finalmente, o artigo de Miguel Serna discute a problemática das mudanças na composição das elites empresariais do último ciclo de globalização econômica neoliberal. Para isso, examina tanto a literatura comparada sobre as recentes elites empresariais quanto os estudos já desenvolvidos sobre o Uruguai. Defende a hipótese de que já há mudanças nas elites empresariais uruguaias com crescente importância do capital transnacional e de novos grupos de executivos que se apoiariam mais em uma forma de controle e gestão profissionalizada das empresas, redes globais e novas formas de capital social, o que contrastaria com os perfis tradicionais empresariais baseados no capital familiar herdado e em círculos empresariais exclusivos.

Maria do Socorro Sousa Braga (msbraga2009@gmail.com) possui doutorado e pós-doutorado em Ciência Política pela Universidade de São Paulo (USP). Atualmente é professora e pesquisadora da Universidade Federal de São Carlos (UFSCar).

Bruno Bolognesi (brunobolognesi@gmail.com) é professor da Universidade Federal da Integração LatinoAmericana (Unila) e doutor em Ciência Política pela Universidade Federal de São Carlos (UFSCar).

\section{REFERÊNCIAS BIBLIOGRÁFICAS}

ÁLVARES, M. L. M. 2008. Mulheres brasileiras em tempo de competição eleitoral: seleção de candidaturas e degraus de acesso aos cargos parlamentares. Dados, vol.51, n.4, p. 895-939.

BRAGA, M. S. S. 2009 Reclutamiento partidario y representación: selección de candidatos a la Cámara de Diputados en Brasil. In: FREIDENBERG, F. \& SÁEZ M. A. (orgs.). Seleccion de Candidatos, política partidista y rendimento democrático. $1^{\mathrm{a}}$ ed. México: Tribunal Electoral del Distrito Federal e Instituto de Iberoamérica.

\& BOLOGNESI, B. 2013. Dimensões do Processo de Seleção da classe política brasileira: autopercepções dos candidatos à Câmara dos Deputados nas eleições de 2010. In: SANTOS, A. M. Os Eleitos. Representação e carreiras políticas em democracias. Porto Alegre: Editora UFRGS, 2012. 
CAMP, R. A. 2001. Political Recruitment across Two Centuries. Mexico, 1884-1991. Austin: University of Texas Press.

CARDOSO, F. H. 1975. Partidos e deputados em São Paulo . O voto e a representação política: In LAMOUNIER, B. \& CARDOSO, F.H. (orgs.) Os Partidos e as Eleições no Brasil. Rio de Janeiro: Paz e Terra.

CZUDNOWSKI, M. M. 1970. Legislative Recruitment under Proportional Representation in Israel: a Model and a Case Study. Midwest Journal of Politcal Science, vol. 14, n. 02, p. 216-248, May.

1975 Political Recruitment, In GREENSTEIN F. I. \& POLSBY N. W. (eds.). Handbook of Political Science: Micropolitical Theory. vol. 2 Reading, MA: Addison-Wesley.

EPSTEIN, L. D. 1967. Political Parties in Western Democracies. New York: Praeger.

FLEISHER, D. 1976. Thirty years of Legislative Recruitment in Brazil: an analysis of the social backgrounds and carrer advancement patters of 1548 federal deputies, 1945-1975. Edinburgh, $10^{\circ}$ Congresso Mundial da Associação Internacional de Ciência Política - IPSA.

FREIDENBERG, F. 2003. Selección de Candidatos y Democracia Interna en los Partidos de América Latina. Série Biblioteca de Reforma Política, n. 01. Lima: IDEA.

GALLAGHER, M. \& MARSH, M. 1988. Candidate selection in comparative perspective: the secret garden of politics. London: Sage Publications.

HAZAN, R. Y. 2002. Candidate Selection. In: NIEMI, L. GUNTER, R. \& NORRIS, P. Comparing Democracies. London, Thousand Oaks, New Delhi: SAGE Publications.

\& RAHAT, G. 2006. Candidate Selection. In: KATZ, R. \& CROTTY, W. (eds.), Handbook of Party Politics. London: Sage.

2010. Democracy within Parties. Candidate Selection Methods and Their Political Consequences. New York: Oxford University Press.

KOOP, R. \& BITTNER, A. 2011. Parachuted into Parliament: candidate nomination, appointed candidates, and legislative roles in Canada. Journal of Elections, Public Opnion and Parties. vol. 21, n. 04, p. 431-452.

LEOPOLDI, M. A. 1973. Carreira Política e Mobilidade Social: o legislativo como meio de ascensão social. Revista de Ciência Politica, v.7, n.2, p. 32-58.

1977. Estado e Representação de interesse no Brasil-um estudo sobre o legislativo brasileiro e os representantes politicos na Guanabara. Rio de Janeiro. Tese de Mestrado, IUPERJ.

MADURO, L. A. P. 1973. Socialização e Participação Política do Candidato Carioca. Revista de Ciência Política, vol. 7. n. 2, p. 54-76.

et alli. 1971. Notas de Pesquisa: estudos de representação política no Estado da Guanabara. Eleitos em 15.11.1970. Revista de Ciência Política, vol. 5. n. 4, p. 42-64.

MESSENBERG, D. 2002. A elite parlamentar do pósconstituinte: atores e práticas. Brasília: Editora Brasiliense.

MOREIRA, M. T. 1967. A renovação dos quadros políticos na Guanabara. Revista de Ciência Política, V.1, n. 1, p. 25-41.

NORRIS, P. 1997. Passages to Power: legislative recruitment in advanced democracies. Cambridge: Cambridge University Press.

\& LOVENDUSKI, J. 1995. Political Recruitment. Gender, Race and Class in the British Parliament. Cambridge: Cambridge University Press.

NUNES, E. O. 1977. Quem representa o carioca? Dados, n.16, p. 28-45.

1978. Legislativo, Política e Recrutamento de elites no Brasil. Dados, n.17, p. 68-83.

PITTA, N. A. M. \& ARRUDA, J. M. 1966. Composição Sociológica da Assembléia Legislativa do estado da Guanabara. Revista de Direito Público e Ciência Política. vol. 9, n. 3, p 65-81.

RAHAT, G. \& HAZAN, R. 2001. Candidate selection methods: an analitycal framework. Party Politics. vol. 07, n. 03, p. 297-322, May.

\& KATZ, R. S. 2008. Democracy and Political Parties. On the uneasy relationships between participation, competition and representation. Party Politics. vol. 14, n. 06, pp. 663-683, Nov.

RODRIGUES, L. M. 2002. Partidos, Ideologia e composição social. Um estudo das bancadas partidárias na Câmara dos Deputados. Sâo Paulo, EDUSP.

. M. 2006. Mudanças na classe política brasileira. São Paulo: Publifolha. 
RUSH, M. 1969. The Selection of Parliamentary Candidates. London: Thomas Nelson and Sons.

SANTOS, A. M. 1997. Nas fronteiras do campo politico: raposas e "outsiders" no Congresso Nacional. Revista Brasileira de Ciências Sociais, São Paulo, vol. 12, n. 33, p. 87-101, Fev.

SAMUELS, D. 2008. Political Ambition, Candidate Recruitment and Legislative Politics in Brazil. In: SIAVELIS, P. \& MORGENSTERN, S. Pathways to Power. Politcal Recruitment and Candidate Selection in Latin America. University Park, PA: Pennsylvania State University Press.

SIAVELIS, P. M. \& MORGENSTERN, S. 2008.
Pathways to Power: Political Recruitment and Candidate Selection in Latin America. University Park, PA: Pennsylvania State University Press.

SIAVELIS, P. \& MORGENSTERN, S. 2009. Reclutamiento y selección de candidatos en América Latina: un marco para el análisis. In: FREIDENBERG, F. \& SÁEZ M. A. (orgs.). Seleccion de Candidatos, política partidista y rendimento democrático. $1^{\mathrm{a}}$ ed. México: Tribunal Electoral del Distrito Federal e Instituto de Iberoamérica.

SCHMITTER, P. C. 1971. Interest Conflict and Political change in Brazil. Stanford: Stanford University Press. 